Article

\title{
Sustainable Construction through Industry Self-Regulation: The Development and Role of Building Environmental Assessment Methods in Achieving Green Building
}

\author{
Roine Leiringer \\ Department of Real Estate and Construction, University of Hong Kong, Pokfulam, Hong Kong, China; \\ roine.leiringer@hku.hk
}

Received: 1 September 2020; Accepted: 16 October 2020; Published: 25 October 2020

\begin{abstract}
The role of industry self-regulation in facilitating sustainable development has gained increasing recognition over the past two decades. As a result, voluntary certification standards have become ever more common and have been portrayed as effective means of enforcing more environmentally beneficial practices across a range of industries. In this paper, we consider the role of one such type of standard, building environmental assessment methods (BEAMs), and the role they have played in the transition towards green building in the construction industry. Drawing on the theory of strategic action fields, and using the case of HK BEAM in Hong Kong, we investigate the origins, development and impact of BEAMs in what is a highly de-centralised and fragmented industry. The paper concludes with reflections on the need to extend focus from the contents of the BEAMs in terms of categories, criteria and weightings, to instead more actively consider the "taken-for-granted" assumptions around sustainability and the dominant institutionalised practices in construction.
\end{abstract}

Keywords: building environmental assessment methods; green building; industry self-regulation; sustainable construction; voluntary certification standards

\section{Introduction}

The importance of the built environment for sustainable development has progressively been emphasised over the past three decades (cf. [1,2]). Construction has, thus, come to be held accountable for major sources of environmental damage and a variety of mandatory and voluntary drivers for firm and sector-level change have emerged to affect change in the industry. In response, various new or improved materials, technologies, processes and management tools have been introduced into organisational and project settings. In broad terms, these attempts have had an impact in some areas, but have led to few, if any, advances in many others [3,4]. Overall progress has been repeatedly criticised for being slow, patchy along the value chain, and failing to have a significant, enduring impact; with a chasm existing between embedded practice and what is technically possible (e.g., [5-7]). It is clear that the construction industry has the technical know-how to build sustainable buildings; what it chooses not to, or does not know how to do, is to incorporate that know-how into embedded practice. Hence, while there are numerous examples of successful measures taken on individual projects, construction firms struggle with incorporating the associated sustainable practices into their everyday practice, across projects. This makes sustainable development in construction as much an organisational issue as it is a technological one (cf. [1,2]).

This paper takes as its point of departure that while national legislation asserts coercive pressure on the construction industry through building regulations many of these are prescriptive in nature 
and focus on individual building elements. They do, as such, not effectively deal with wider more holistic sustainability issues. Broader policies and directives also partially miss the target in terms of sustainable development, as they tend to address the building and activities undertaken in the building rather than the construction process itself [8]. It follows that, firms involved in the construction process are not greatly affected by, for example, fiscal and market-based policy instruments, such as emissions- and carbon trading. Indeed, apart from the obvious case of construction waste management, much of the actual construction process falls under the radar of many traditional command and control regulations (cf. [9]). As a partial remedy, the industry has engaged in self-regulation [10] and a wide variety of voluntary benchmarks, certification programmes, frameworks, indices and standards have been developed [11,12].

In this paper, we are interested in voluntary certification standards as a means of self-regulation in the construction industry. Our focus is on the development and implementation of building environmental assessment methods (BEAMs), and the associated certification of buildings. The effect of BEAMs on construction practice and in achieving more sustainable development has received substantial attention in the literature (e.g., [11-16]). Indeed, the literature is replete with studies that have sought to compare the contents of different BEAMs (e.g., [17]), suggested new criteria, measures and weightings for BEAMs (e.g., [18]), compare results across BEAMs (e.g., [19]), and sought to illicit success factors for BEAMs (e.g., [20]). Our interest, however, moves beyond the actual contents to also focus on their creation and use. We seek to build on the small, but growing literature that explores the role of these voluntary certification standards in affecting institutional change and potentially forming new institutional fields with actors converging around institutional logics and practices more aligned with sustainable construction (e.g., [21-24]). Our aim is to explore the role of BEAMs as a policy tool put in place to affect change in the form of new green building practices.

The paper is structured as follows. We begin by introducing the concepts of industry self-regulation and voluntary certification standards. Particular attention is given to motivational factors behind self-regulation, intended and unintended outcomes, and how much of our knowledge comes from studies of highly centralised regulated industries, rather than project-based industries, such as construction. This is followed by a description of construction and how it could be understood as a highly fragmented industry. The argument is then turned to the emergence of BEAMs and how they have come to be seen as a way to operationalise "green building". Particular attention is given to the development of BEAMs and the many claims that have been made around their effect on, and ability to change, practices in the building industry. The theoretical framework, theory of strategic action fields, as put forward by Fligstein and McAdam [25,26] and Fligstein [27], is then introduced and the main implications for understanding field level change is elaborated upon. We then present the adoption of a particular BEAM, HK-BEAM, as an illustrative example and use findings from a longitudinal case study of its creation, development and adoption in Hong Kong to discuss the effect of BEAMs on institutional logics and practices; why they are yet to generate the kind of changes in construction practices that their proponents claim are possible.

\section{Industry Self-Regulation and Voluntary Certification Standards}

Industry self-regulation is the voluntary coming together of firms to control their collective behaviour [10]. It entails firms in an industry coming together in creating and voluntary abiding by a set of governing rules [28]. Such practices include the creation of standards, certification programmes, indices and benchmarks, amongst others [14]. Our interest is in the use of the voluntary certification standard. The distinguishing feature of which is the existence of a means of certifying compliance with a defined set of practices [29]. Thus, it goes beyond voluntary codes of conduct and self-regulatory modes of governing, by adding a third-party verification that either the organisational practices, or the end-product, has met the defined standards of performance. In other words, voluntary certification standards have two fundamental elements: they (i) codify a set of standard practices and (ii) provide a certification system that allows organisations to communicate their application of these practices [29]. 
In general terms, the creation and administration of certification standards involves: the setting of standards based on the use of "scientific" norms and practices; traceability and auditing; labelling of the products that meet the standards; and the establishment of an organisation that can perform these functions [30].

Voluntary certification standards are created at industry or sub-industry levels and it is not uncommon that powerful actors, such as large organisations and government agencies, play a leading role in their creation and widespread adoption, as has been the case in, for example, the automobile and chemical industries (cf. [23]). Individual firms may choose to pursue voluntary certifications for a variety of reasons. They might, for example, wish to differentiate their product/service, seek to retain legitimacy in the eyes of their stakeholders, or seek to avoid government-imposed regulations [22]. In terms of differentiation, the "label" provided through successful certification has been found to be a powerful marketing tool, in particular for early movers [24,31], as it provides a supposedly neutral guarantee that the product/service is more sustainable/environmentally friendly than a non-certified counterpart. As for gaining and maintaining legitimacy, this is fundamentally about aligning with the normative and cultural-cognitive expectations of stakeholders, who are not necessarily the customers/consumers [32,33]. Indeed, these stakeholders come in many forms, such as end-users/consumers, various local interest groups, and environmental organisations more broadly. Depending on the circumstances, these actors have the ability to put substantial pressure on firms and they have a whole raft of actions at their disposal that could lead to future government regulation, as well as affecting both customer demand and the individual firm's ability to hire and retain quality employees. Finally, in terms of avoiding regulation, the argument is that voluntary standards are more flexible than state imposed regulations [34]. Coming together under a "neutral" voluntary association and certification standard allows for a unified front, which is able to lobby against government policies and regulation that might otherwise be imposed $[10,28]$.

A key aspect of certification, which has received significant attention in the literature (cf. [29]) is the extent to which the label (certification level acquired) remains coupled to the actual implementation of the prescribed practices, and if the end product truly reflects the aspired to standards. In other words, if the label actually represents what it is supposed to represent. Common explanations for decoupling include that, even if there is an auditing function in place, full scale monitoring and assurance is costly and third-party certification does not guarantee honesty in reporting; there are no guarantees that changes will not take place after certification has been awarded (ibid.). Issues of decoupling aside, voluntary certification standards have come to be considered as a powerful force for encouraging whole industries to adopt socially and environmentally beneficial practices [35]. They are seen not only as a label for certain products fulfilling specified criteria, but also as tools that affect the practices and strategies of firms [10]. However, in much of this literature, the model is highly centralised regulated industries, such as traditional manufacturing, where firms have extensive control over the production process [36]. This contrasts starkly with the situation in construction for a number of reasons, as will be discussed next.

\section{The Nature of Construction}

Construction plays an important role in the economy as it produces and maintains the built environment. Predominantly, construction follows advances in other sectors of the economy, such as the extension of transportation networks, increased commercial activities and migration to urban areas etc. Furthermore, and of importance to the argument progressed in this paper, construction is a derived demand, meaning that construction work, in economic terms, often is one or two steps removed from the final customer/user [37].

With few exceptions, construction work takes place at the point of purchase. This is in contrast to the traditional practice within manufacturing firms whereby goods are fabricated before being moved to a sales location and then sold to the customer. The construction sector consists of a large number of firms active in distinct markets. There will, in any country, be numerous regional markets and 
submarkets and in these submarkets, there are usually a few firms that dominate the supply of the product, material or service. The construction sector is in itself a network of interrelated markets for equipment hire, labour, materials and components etc., that interact to produce the final product on site. These markets might or might not produce solely for the construction industry. In consequence, the construction industry consists of different types of specialist firms working together on temporary sites to produce, repair and maintain buildings and civil engineering works. Projects are geographically dispersed, transient and separated in time. This has led to the industry being dominated by very small firms. Around $98 \%$ of the firms on a national market will be Small and medium sized enterprises (SMEs) operating in a limited geographical region. These firms typically operate at very low profit margins and are entirely reliant on cash flow [38]. It is noteworthy, however, that the relatively few large firms still contribute a comparatively large part of the construction value output. In the UK, for example, $0.1 \%$ of the firms account for around $25 \%$ of the total turnover in the industry (ibid.).

Actors within the construction industry have to document compliance with building regulations in order to obtain a building permit. They are then subjected to inspections from the relevant authorities up until the completion of the project. The regulatory systems vary between countries, both in terms of the degree to which regulations, codes and norms are nationally or locally enforced, as well as if they are prescriptive or performance based. Prescriptive regulations dictate attributes such as material and production specifications for building components, while performance-based regulations target certain performance criteria, such as overall strength or level of insulation. Thus, prescriptive regulations involve standards specifying materials, configurations, and practices required to achieve a certain regulatory goal, while the performance-based regulations mainly specify the regulatory goal. Regardless of how they are specified, building regulations are commonly used to specify minimum functional requirements, which differ in accordance to building type; effectively limiting the incentives for any firm to go beyond compliance on individual projects [3].

In short, construction is in many ways the epitome of a project-based industry. De-centralization and dispersed modes of working in inter-organisational projects are defining characteristics of the industry (cf. [39]). Clients and end-users are rarely the same, and even large repeat clients have their projects spread across time and space [40]. Tendering procedures commonly focus on price, rather than highest value with lowest waste and cost, and the clients are not necessarily the end-users. Projects are temporary, often highly customized, and rarely undertaken within a standard framework. They are characterised by long supply chains, extensive use of sub-contracting and an emphasis on short-termism [41]. Production, hence, involves not only non-routine production processes, but also complex inter-professional and inter-organisational contractual and working relationships that govern project-based interaction. Moreover, project teams are heterogeneous, consisting of a mixture of staff from different professional and organisational backgrounds. The phasing of project activity across and within design and construction stages and the transient and time-pressured nature of project activity leads to regular secondment and movement of staff between projects being common. It also leads to that project management practice is deeply influenced by ingrained institutional practices and norms [42].

\section{Green Building and the Emergence of Building Environmental Assessment Methods}

The concept of "Green Building" emerged in the 1990s as various industry actors started to seek ways to mobilise in response to the increasing external pressure put on them to alleviate the negative impact of construction activities on the environment (cf. [43]). The development and rise in prominence of BEAMs and various other forms of environmental assessment schemes in the late 1990s can be understood as part of this broader "green building" movement. Early, influential certification schemes include BREEAM in the UK (introduced in 1990), HK-BEAM in Hong Kong (introduced in 1996) and LEED in the USA (introduced in 1998) [13]. The schemes were promoted as a means to provide a degree of objectivity in classifying practices and products as "sustainable" or "unsustainable" [12]. Hence, they were seen as a way to operationalise the rather elusive concept of "green building", both as a noun, 
i.e., as a label for an environmentally friendly building, and a verb, i.e., the sustainable practices that produce the building. Providing them with a status of being green building "guidelines" [14,44,45].

\subsection{BEAMs and Their Role as Certification Standards}

Today, a BEAM can be understood to fulfil all the criteria set out for a voluntary certification standard. It is an assessment tool, which is accompanied by some form of third-party registration and certification. BEAMs invariably consist of a framework of categories corresponding to different aspects of green building. Each category consists of a variety of performance criteria and other measures, all of which are divided into sub-categories and assigned a certain number of credits. Many of these criteria are in the form of compliance with prescriptive building regulations, norms and codes, and hence specify what could be considered to be well established standard practices. Assessment is undertaken through the project team producing documentation to establish their compliance with the set criteria. The evidence is compiled by an assessor and sent off to a certifying body, which evaluates the application and comes back with a score. The scores are divided into bands that relate to a certain certification level typically taking the form of a singular, straightforward label following an intuitive scale, e.g., "Excellent" and "Good" or "Platinum" and "Silver" etc.

There are currently several hundred BEAMs in use across the world [14,46]. These are, with a few exceptions, developed and owned by a non-state organisation that oversees the implementation. Government agencies are usually involved in the development of BEAMs in some way, and they normally have a place on national green building councils. Their role is, however, typically minor in terms of dictating the specific contents of the standards. Organisations that own and operate BEAMs are responsible for the maintenance and continuous improvement of these schemes. These organisations organise training and educational programmes, run professional accreditation, provide third-party certification of projects, facilitate the information handling infrastructure and are responsible for the marketing of the scheme. As they are viewed as neutral "brokers" of green building practices, the credibility and legitimacy of these organisations is critical in terms of the authority, acceptance and uptake of the certification standard [47].

Many countries have their own "domestic" BEAM developed with the particular national context in mind, which normally tend to enjoy state support. However, some BEAMs have been imported into other contexts and are widely used in many countries, e.g., UK-BREEAM and US-LEED. For the organisations behind these multi-national schemes the environmental performance assessment of buildings has become big business, with significant revenues generated through the certification process, licensing, training and education and the accrediting of professionals [48]. In the national context, most BEAMs are amended over time and new versions are released on a relatively frequent basis. It is also not uncommon that new BEAMs are developed to compete with and replace the old ones. These are usually referred to as "second" generation BEAMs [49].

Governments in numerous countries, e.g., Australia, Finland, Hong Kong, Singapore, Sweden, the UK, are increasingly incentivising and mandating the use of BEAMs. In Singapore "Green Mark" certification became mandatory in 2008 for all new buildings and existing buildings undergoing major retrofits [50]. In the UK, mandates to reach certain "BREEAM" certification requirements have-since 2000—covered all new government building projects [12]. Hong Kong has adopted a more relaxed mandate. Since 2013, new government buildings with a floor area of more than $5000 \mathrm{~m}^{2}$ are required to aim to attain gold level or above for "HK-BEAM+". Incentives for private developers have also been put in place since 2011 in the form of registering for HK-BEAM+ certification being one of the criteria for a 10\% GFA (gross floor area) concession being granted [51]. However, there is no requirement for a final certification to be obtained at the end of the project [52].

\subsection{The Value of BEAMs}

Numerous claims have been made regarding the value of BEAMs and the role they play in the construction industry. These can be summarised as follows [11,14,43,46]: 
- Define environmental standards in terms of criteria and targets;

- Allow for the demonstration of achievement in terms of meeting these standards and differentiating "green" buildings from "non-green" buildings;

- Provide a means of documenting and structuring environmental information;

- Facilitate for manufacturers of green building materials and products to make direct and indirect associations with the relevant performance criteria;

- Allow for building owners (public and private) to demonstrate commitment towards sustainability;

- Communicate the environmental qualities (greenness) of the building to prospective buyers and users;

- Improve public awareness of sustainable building;

- Provide a reference point for public and private sector clients to develop environmental strategies and operationalise sustainable development goals.

Proponents commonly proclaim a range of additional positive effects, including more efficient resource use, lower operating costs and enhanced indoor environments (cf. [53]). Furthermore, less easily measurable benefits, such as enhanced reputation are also brought forward; applying to both the certified buildings as well as the actors who have subjected themselves to requirements associated with certification $[21,54]$. This argument is then extended to that being involved in green building and occupying green buildings both contribute to organisations either gaining or maintaining legitimacy on their market $[22,23]$.

In summary, by laying down the fundamental direction for industry actors in adopting green building practices, the use of BEAMs is seen as enhancing the overall environmental awareness in the construction industry [45]. In this way, BEAMs have, for some, come to be considered as one of the most potent and effective means to both improve the performance of buildings and to transform market expectations and demand, and hence playing a significant role in "mainstreaming green building practices" (cf. $[47,55]$ ). Put somewhat differently, BEAMs are seen as a means of introducing new institutional logics and practices into construction [23] and forming the basis for a new institutional field of "green building", in which such logics and practices are dominant [21].

\section{Theory of Strategic Action Fields}

To explore the context within which BEAMs are developed and implemented we draw upon the theory of strategic action fields, as put forward by Fligstein and McAdam [25,26]. This theory builds on, and brings together, existing work in neo-institutional theory, political and organisational sociology, and social movement theory [56-58]. As a theory of stability and change it allows for the reconciliation of the reproduction of social order and the production of social change $[27,56,59]$.

Strategic action fields (SAFs) are conceptualised as the fundamental units of collective action in society. They are social arenas in which individual and collective actors, such as groups, firms and organisations contend for resources, privileges and gains. Fligstein and McAdam [26] define a strategic action field as "a meso-level social order where actors (who can be individual or collective) interact with knowledge of one another under a set of common understandings about the purposes of the field, the relationships in the field (including who has power and why), and the field's rules" (p. 3). Four key features govern the SAF. First, a general shared understanding of what is going on in the field, i.e., what is at stake (cf. [60]). Second, actors understand their role and position in the field, i.e., how power is distributed. Third, shared understandings regarding the nature of the formal and informal "rules" in the field, i.e., what tactics are possible, legitimate and interpretable for the different roles in the field. Fourth, there are shared broad interpretive "cultural" frames that actors use to make sense of what others are doing.

SAFs can be emergent, stable (reached settlement) or in transformation, and consist of incumbents, challengers and internal governance units $[25,26]$. The "incumbents" wield a large degree of power and have a disproportional influence over the field. Their interests and views are reflected in the dominant 
organisation of the field. As such, the purposes and structure of the field are adapted to their interests. They are also the actors who get most of the valued objects (e.g., material and status rewards) in the SAF. Established rules tend to favour them and the dominant shared meanings tend to legitimise and support their privileged position. Hence, incumbents are powerful actors with sufficient political and material resources to dictate the view of appropriate field behaviour and definition of field membership. "Challengers" occupy less privileged niches within the field and they wield little influence over its operation. Thus, they conform to the prevailing order, despite finding themselves at a disadvantage in the field, but seek ways to challenge the status quo. Usually challengers articulate alternative visions for the field and their position in it. The "internal governance units" (IGUs) oversee compliance with field rules and facilitate the smooth functioning of the system and the reproduction of the field. IGUs are internal to the field and should be distinguished from the external state structures holding jurisdiction over it (such as laws and regulations). The IGU ensures the routine stability, or order, of the SAF and mainly serves five functions: administration, information, regulation, enforcement and certification, i.e., they serve to reinforce the dominant logic(s) in the field. Finally, SAFs do not exist in isolation. Rather they are intimately tied to the broader environment and are embedded in, and affected by, other SAFs. These relations to other fields powerfully shape the development of the SAF, and also dictate the degree of stability achieved [27]. In short, an SAF is embedded in a complex web of other fields.

\section{The Evolution and Impact of HK-BEAM}

In the discussion that follows, we use HK-BEAM in Hong Kong as an illustrative example rather than inductively deriving theory from a qualitative case study. Our focus is on telling a good story [61] rather than to portray quantifiable data and findings that could be generalised across contexts. In following qualitative research traditions we seek transferability, which we illustrate by drawing on research findings from other geographical contexts. The illustrative case is based on a study of the development and implementation of HK-BEAM in Hong Kong conducted between 2016-2019. The research was conducted in two stages. The first stage consisted of archival analysis to: (i) track the development over time of the contents of the 14 different versions of HK-BEAM, including inclusions and exclusions and changes in criteria, measurement and credits (this also includes meeting minutes where available); (ii) record changes in the membership of BEAM Society and the HK Green Building Council and their predecessors, as well as of the committees and sub-committees responsible for the development work of HK-BEAM, since its first version; (iii) map an official sustainable construction/green building policy discourse by content analysis of a total of 71 government policy documents (annual, environmental and sustainability reports) from five government departments over the period 1999-2018, and 19 Hong Kong chief executive policy addresses between 1999-2018; (iv) map a sustainable construction/green building industry discourse through content analysis of the corporate annual and sustainability reports of three large contractors and three large consultancy firms plus three professional bodies over the period 1998-2018 (110 reports in total); (v) map the involved main actors in 144 certified projects completed by the end of 2017. The second stage was to corroborate the emerging story coming out of stage one through interviews and informal discussions with: individuals who have at one stage or another been involved in the development of HK-BEAM; representatives of leading clients; practitioners working in different roles on BEAM projects for contractors and specialist service firms, and sustainability directors, or the equivalent, of three main contractors and two large consultancies. Additionally, a number of formal events organised by a variety of public and private actors, such as awards, public consultations and release events were attended.

\subsection{A Brief History of HK-BEAM}

The development of HK-BEAM was initiated by the Real Estate Developers Association of Hong Kong (REDA), who provided the funding for the establishment of the BEAM Steering Committee in 1995. Other founding members were the Planning, Environment and Lands Bureau, the Business 
Environment Council and the Hong Kong Polytechnic University. The first assessment tool was launched in 1996 and covered new and existing air-conditioned office buildings. It was mostly the result of the academic members adapting the UK BREEAM scheme to the Hong Kong context. In 1998, the Hong Kong Housing Authority, one of the biggest providers of public housing in the world, joined the BEAM Steering Committee. This led to the development of a new version of the tool in 1999, which included high-rise residential developments. In 2002, the BEAM Steering Committee was formalised into the HK-BEAM Society, with the membership essentially remaining as it was. A third version of the tool was subsequently released in 2003 to cover both existing and new buildings, and updated versions were released in 2004 and 2005. The Hong Kong Green Building Council (HKGBC) was formed in 2009 by the HK-BEAM Society, the Construction Industry Council, Business Environment Council and Professional Green Building Council. Significant changes took place in 2010. The HK-BEAM Society was transformed into BEAM Society Limited and two new versions of the assessment tool were introduced together with a change of name to BEAM+, signifying extensive changes in contents and intent. After this, several more revised versions have been released along with new assessment tools for building interiors, and neighbourhood design. There are currently at least 16 versions of HK-BEAM certification standards in active use.

\subsection{Heroic Champions or Strategic Actors?}

As previously noted, powerful actors often play a leading role in the development of voluntary certification standards and the subsequent adoption is frequently credited to their "heroic" leadership (cf. [23]). BEAMs are seemingly no different. The first BEAM, the UK BREEAM, was created as a design and construction tool for new offices by the governmental scientific research institute "Building Research Establishment" at the request of a large developer [62]. Similarly, the development of HK-BEAM was initiated by two of the largest and most influential developers of commercial properties in Hong Kong, through their membership in REDA. The addition of the Hong Kong Housing Authority in 1998 added the largest housing developer in Hong Kong to the core group of organisations, championing the standard. However, the membership of the BEAM society and the working groups concerned with the development of the certification standards changed significantly between 2004 and 2010. During this period a second generation BEAM had been developed, Comprehensive Environmental Performance Assessment Scheme for Buildings (CEPAS), through an initiative led by the Hong Kong Buildings Department and a world leading engineering consultancy. It had the backing of a number of leading contractors and engineering consultants that had not been involved in the development of HK-BEAM [53], and was at the time of its launch in 2005 marketed as addressing environmental concerns not incorporated in HK-BEAM [49]. CEPAS was never adopted on the market and no project has been certified, but many of the organisations involved in its development took on prominent roles in the BEAM Society. As a result, the membership in the steering committees and working groups changed ahead of the release of BEAM+, with supply side actors becoming dominant. Hence, what started off as an initiative driven by powerful clients with the development work undertaken by academics based on BREEAM, had relatively quickly been taken over by powerful suppliers in the form of contractors and engineering consultants.

\subsection{Green Building Discourse - A Recursive Relationship or Industry Staying One Step Ahead?}

Sustainable development initially appeared in the Hong Kong chief executive's policy address in 1999. The Buildings Department first mentioned "green building" in 2000 and it would in the years that followed-together with other departments, such as the Architectural Services Department-mention various criteria included in the HK-BEAM standards. But it was not until 2010 that green building as a concept made it onto the highest level of governmental policy, i.e., the chief executive's policy address. The following year saw increased importance and weight given to the green building and explicit mentions were made of the "green building sector" and "green building certification". Focus on the concept culminated in 2013 with the establishment of the "inter-departmental steering committee on 
green building". After this, specific mentions of green building and HK-BEAM have become less and less common, replaced by a more direct focus on energy reduction and carbon emissions.

Amongst the contractors and consultants, occasional mention of green construction and sustainable buildings emerged in corporate documents in 2002. More prominent and frequent mentions started in 2008 and the terminology featured prominently in corporate reports up until 2015. This was accompanied by frequent mentions of BEAMs in general, and BEAM+ in particular, between 2011 and 2015. Since 2016 mentions have been less frequent, but when occurring, commonly directly address the public sector discourse on carbon and energy.

\subsection{Decreasing Environmental Impact or Introducing Greater Flexibility?}

The contents and coverage of the HK-BEAM has broadened over the years. The first version for new buildings released in 1996 was 193 pages and consisted of three main categories and 19 sub-categories, in which credits were awarded. The latest version (released in September 2019) is 341 pages and has seven categories and 22 sub-categories. As of April 2020, 13 projects had registered for this standard [63]. There is no doubt that the current versions of HK-BEAM are exceedingly more sophisticated than the early versions. The coverage is now much broader, including more categories and criteria. Furthermore, the measures have moved from being mostly functional and prescriptive in nature to more performance based. These should be considered as positive changes, but at the same time it means that there is more room to pick and choose which credits to go for. It also means that there are likely to be significant differences between buildings achieving the same label under the certification standard. Equally important, there is little that allows for comparison between buildings assessed by the early versions of HK-BEAM and those certified under the more recent BEAM+ standards. The move to change the labels from good, very good, excellent to silver, gold, platinum is an attempt to deal with this issue. Yet, according to the interviewees this is deemed to have worked for primary stakeholders, such as large client organisations, but is considered to have had little meaning to, and caused further confusion among, the more peripheral external stakeholders like the general public.

\subsection{The Uptake of HK-BEAM}

In terms of uptake, HK-BEAM has often been credited for having certified the most square- meters of building per capita of any BEAM [64]. This should, however, be put into the context of the relatively small population of Hong Kong and the high rise nature of its urban landscape. Up until the release of BEAM + in 2010, just over 100 buildings had achieved a final certification [65], and as of early 2020, 438 projects had passed final assessment using some version of BEAM+. Out of these 438, 106 achieved the highest classification Platinum, whilst 68 projects failed to get a classification. In terms of new buildings, 275 projects have reached final assessment under BEAM+, of which more than half (143) have received a final certification of silver or below [63]. This is noteworthy in relation to the Hong Kong GFA concession scheme, which was enacted in 2011, and its perquisite of attaining gold or higher. While this scheme had an immediate effect on the market with the number of registered BEAM Plus projects almost doubling over four years $[66,67]$ many projects clearly did not go through with the certification, or settled for a lower score (label). This is in line with findings from other countries, such as New Zealand and the USA [62].

While not statistically conclusive, our analysis of 144 fully certified projects completed before the end of 2017, points towards the main actors involved being the same as would be expected to be found on non-certified house building projects of similar size and scope. Of greater interest, however, is the rather clear correlation between membership participation in BEAM society committees and $\mathrm{BEAM}+$ working groups and participation on certified projects. Or put somewhat differently, firms with leading roles in the HKGBC and the BEAM Society tend to, in comparative terms, have been active on the most certified projects in our sample. 


\section{Discussion}

HK-BEAM as a voluntary certification standard meets the criteria for successful industry self-regulation. The content of the standards is produced by a number of working groups adopting "scientific" norms and practices. Auditing is provided through the BEAM Society and there is a degree of traceability. Labelling of the buildings that meet the standards is carried out by the HKGBC, lending weight to the label. Furthermore, HK-BEAM has found its way into the policy discourse, both in connection to sustainable development and green building. There is also a degree of awareness of the label within certain layers of society as the "plaques" showing the certification feature prominently on several landmark buildings and leading firms, both on the client and supply side, promote their involvement in high profile projects on their websites, as well as in promotional and corporate documents. However, the actual uptake of HK-BEAM has so far been limited in relation to the overall output in the building sector in Hong Kong, and large parts of the industry remain unaffected by the certification standard.

A number of explanations for the low levels of impact can be identified. A first explanation has to do with the nature of building construction. In most countries repair and maintenance constitute $40-50 \%$ of building work [38] and most of these projects are not suitable for certification. Indeed, out of the $600+$ projects currently (spring 2020) registered under BEAM+ only $~ 10 \%$ are for existing buildings. A second explanation can be found in the perceived and real extra costs associated with certification. It is, unfortunately, close to impossible to say anything definitive about construction costs, as these are enshrouded by commercial sensitivities. Our interviewees estimated increased capital costs to be in the range of 5 to $30 \%$. In a larger, predominantly Hong Kong focused, "perception based" survey Chan and Leung [51] found that the capital costs increase by around $34 \%$, while a study conducted in New Zealand [68] based on actual cost data found them to increase by on average 12\%. Despite the discrepancy in the figures, they still offer insights into why some clients, especially on smaller and lower profile projects either opt not to register for certification or, if they do, not see it through to final assessment. A third explanation commonly linked to increased capital costs is that of different end-user groups willingness to pay premiums, i.e., limitations in market demand can be found in both residential (e.g., [68]) and commercial (e.g, [46]) sectors. Similarly, a fourth explanation is that client organisations often do not end up being the owners and/or end-users of the building; meaning that the increased capital costs are not automatically off-set by efficiency gains in operation. A fifth explanation can be found in the reluctance of parts of the supply chain to participate. There is a significant risk involved for SMEs, as time and cost overruns are not uncommon (cf. $[69,70])$. Given the heavy reliance on a steady cash flow for survival, not all firms are willing to take the risk and will not bid for work on HK-BEAM registered projects.

Notwithstanding the above, from the perspective of the key drivers for industry self-regulation, the relatively limited uptake of HK-BEAM might not necessarily have any greater consequences for its success. As pointed out in our interviews, it is not necessary for the majority of the projects to be certified and provided a label. Construction, and the resultant buildings, is ever present in the urban landscape and most people are subjected to it in some way on a near to daily basis. Yet, this is mostly peripheral and not something that is taken much notice of. Hence, from marketing, legitimacy and avoiding more stringent regulation perspectives, it is enough that big landmark projects are certified, as these are the buildings that will be noticed and spoken about.

\subsection{Decoupling or Business as Usual?}

The story that emerges through our document analysis, interviews and informal discussions with practitioners is one of "business as usual" on BEAM projects. Working on a HK-BEAM registered project is not considered to be much different from working on other "traditional" projects, apart from the increased emphasis on documentation and reporting. While our sample is too small to draw any firm generalizable conclusions, two observations further qualify this finding. Firstly, similar results are reported in the work of Schweber $[12,14,15,71]$, who came to comparable conclusions in her study 
of the adoption of BREEAM in the UK. Secondly, the 2011 inclusion of BEAM in the prerequisites for private sector developments receiving GFA concessions and the 2013 mandating of BEAM+ on government buildings have been almost entirely uncontroversial, and has met with no noticeable opposition in the Hong Kong construction industry. We have found no explicit criticism of either of the two in the press, trade journals or documents produced by professional bodies. This is significant as from a SAF theory perspective, if new policies are seen to put the field at a disadvantage the most likely response is the creation of new temporary alliances in the face of the external threat $[25,27]$. These new coalitions will heavily oppose, or find ways to counteract and work around, the policy's targets.

It is also possible that the reason for the actors involved not experiencing any major differences between projects in terms of working procedures is that they successfully decouple their work from the standard. Given the transient and fluid nature of construction work and the high degree of reliance on self-reporting involved in HK-BEAM certification this is not implausible. However, we found nothing to suggest that there was any false reporting on the projects. What we did come across, however, was what has been dubbed "points mongering". This practice has been reported in numerous publications, especially on LEED certified projects, and is essentially a result of the project team being able to pick and choose between a variety of elective criteria in each category $[4,46,62]$. While HK-BEAM has taken steps to make many criteria mandatory, it is still possible for the project team to actively reject criteria that they deem disruptive to established working practices.

\subsection{A New Green Building Field?}

It lies within the power of the state to directly address aspects of sustainable construction and green building. To do so, it has a number of tools at its disposal, such as laws, regulations, norms, and taxes etc. However, a degree of caution is needed in exercising these options as if they are too radical they might throw the building field into a crisis, and this is not in the state's best interest as a field in crisis will effectively stop its output.

It is a mainstay in neo-institutional theory that major change is driven by "heroic champions" [10] and that change coming from within is more likely to be accepted by the field at large [23]. We do not refute this, but our findings offer an alternative perspective of the consequences of such leadership and how it affects the contents of self-regulation. In the case of HK-BEAM these industry champions, who have taken on a leadership role in the development and implementation of the standard, have belonged to organisations that could clearly be considered as incumbents; initially strong client organisations and then increasingly powerful supply side actors. Of importance here is that incumbents typically enjoy significant resource advantages over field challengers and are, therefore, rarely motivated to challenge the status quo [59]. It would, therefore, go against their own interests to drive through change that would weaken their position in the field [72]. Hence, it is unlikely that a change initiative led, or dominated, by incumbents will lead to any significant change in actual practice and equally importantly in the dominant institutional logics and how the field is structured. This, we argue, has had important ramifications for the development of the contents and subsequent implementation of HK-BEAM as a voluntary certification standard. We would go as far as to argue that by HK-BEAM being picked up in the public policy discourse, mandated on government projects and made a perquisite for GFA concessions the incumbents, and the industry at large, have succeeded in avoiding other more stringent regulations to enforce green building. It is, of course, impossible to say what regulations might otherwise have been imposed had it not been for HK-BEAM, but traditional command and control regulations, such as the addition of landfill charges in the waste disposal ordinance in 2005 [73] and the strengthening of the building energy code in 2009, have since their enactment, undoubtedly had an effect on the industry.

The argument presented above is, however, only partial and does injustice to some of the involved actors, who might well have had genuine sustainable development as their goal. There is, therefore, also a need to take into consideration how projects registered for HK-BEAM fit into the broader building field. Two issues in particular deserve to be the highlighted. The first is the recognition 
that there have been developments around green building outwith the BEAM realm. For example, variations of green building design existed long before the creation of BREEAM and have continued to develop over the past thirty years, drawing on a very different understanding of sustainability, e.g., regenerative design [74]. Hence, there are actors in construction who actively promote sustainable development, but who at most treat BEAMs as filling a small part of this. A second issue is that construction is made up of numerous nested sub-fields. The strengths of the links between the fields determine the likelihood of change occurring in any particular field. Construction firms, be they contractors, consultants, designers or equipment and plant providers are typically project-based firms that frequently work on multiple projects, in different sub-fields, separated in space and time at any particular point. A policy, or as in this case a certification standard, targeting a certain sub-field (such as high-rise residential buildings) and the actors active in this field is unlikely to have any greater impact on "construction" as a whole, unless consideration is taken to the roles and positions the affected actors have in other fields and how these fields are connected. When the power imbalance between two fields is high, i.e., when there are strong unidirectional vertical ties, the structure and institutions in the dominant field are likely to be retained [57]. The end result of which, is that new thinking and practice aligned with green building are likely to remain isolated in terms of the projects in which they occur.

\section{Conclusions}

There is no denying that applying BEAMs lead to buildings that at least partially go beyond mere compliance with the building regulations. Furthermore, there is no question that BEAMs have in some cases lead to high performing buildings. Their implementation has also led to a more extensive use of "environmentally friendly" materials, at least in parts of the Hong Kong market. However, HK-BEAM's impact on the building industry at large has so far been rather limited. The question is, therefore, to what extent BEAMs, as they have been developed and applied, are actually driving green building practices, or if they in reality have become an obstacle for real change to take place.

HK-BEAM can be considered to be a successful attempt at industry self-regulation. It provides criteria and targets for environmental standards, while facilitating the differentiation between "green" buildings that meet these, from "non-green" buildings that do not. Hence, it has allowed certain actors to differentiate their services. It has also allowed building owners (public and private) to demonstrate commitment towards sustainability and serves to communicate the "greenness" of the building to potential buyers and users; as well as providing contractors and engineering consultants and other actors in the industry with a reliable anchor in their sustainability reports. This has undoubtedly served for them to gain and retain legitimacy in the eyes of a broad range of stakeholders. Finally, the fact that the certification standard has been mandated on government projects and incentivised on commercial projects and has, thus, seemingly prevented more stringent government regulations being imposed. However, in terms of affecting change in construction and facilitating genuine sustainable development, our findings show that BEAMs are a weak voluntary certification standard. We attribute this to the nature of construction, to how the industry is structured and projects are undertaken, and how the demand side works as clients are seldom the end-users; but also to how the BEAMs are developed and implemented.

As with all research, there are, of course, limitations to the findings we present in this paper. These limitations are mainly related to access to complete data sets. We have dealt with these limitations through applying various forms of sampling in our data collection, but more importantly, we have been careful with how we present the data and in explicating our findings, taking care not to overextend the conclusions that we draw. This approach, which focuses on the story [61], allows us to make a theoretical contribution in adding to the dominant institutional perspective. In the institutional theory literature, voluntary standards are considered more effective than mandatory standards, as they have been negotiated and agreed upon collectively (through institutional work) by the actors in question and, in consequence, are more likely to be regarded as legitimate [21,23,24]. For this negotiation to take place it is argued that strong "heroic" champions should take the lead. We add to this by showing 
that when incumbents lead the development the standards end up being well-aligned with their interests, which is to retain the status quo in the building field. Furthermore, we show how there is little difference between practices on certified and non-certified projects. The green building field, to the extent that it can even be considered to exist, is deeply nested in the broader building field and has been populated with the same institutional logics and rules of the game. There are clearly vested interests at play, and it could be argued that the incumbents have successfully managed to negate the "threat" of the increased pressure for sustainable development and retained the status quo in the industry.

This leads us to question if BEAMs in their current form will ever have a significant impact on construction practices and lead to genuinely sustainable construction? Our findings point towards that for a step change to take place, there is a need to shift focus from the contents of the certification standards to instead rethink how they are created, the context into which they are introduced, and whose needs they actually fill. This means questioning the membership composition of committees and sub-groups and starting to look for other means of co-development of the standards and the surrounding policies, by including both incumbents and challengers as well as the public sector representatives and policy makers. The project-based nature of construction has to be taken into consideration here. Construction is dispersed in time and space and based on multiple levels of sub-contracting. As project activities are phased, firms work on multiple projects at any one time; making for a very fluent "project team" working on site. It is clear, therefore, that the behaviours BEAMs seek to regulate, are governed by powerful and deeply ingrained institutional logics and norms. These are crucial for project governance and have been developed over an extensive period of time and, hence, are not easily displaced. There is, therefore, a need to extend the scope of focus on sustainable construction from new technologies and materials, and how to achieve results on individual projects; to instead more actively consider the "taken-for-granted" assumptions around sustainability and the dominant institutionalised practices in construction.

Funding: This research work was funded and supported by the Research Grants Council of the Hong Kong Special Administrative Region, China (GRF: Project No. HKU 17250116).

Acknowledgments: The author wishes to acknowledge and thank Yan Fang and Xiaoyu Mo for their research assistance.

Conflicts of Interest: There is no conflict of interest.

\section{References}

1. IPCC. Climate Change 2007: Mitigation of Climate Change: Contribution of Working Group III to the Fourth Assessment Report of the Intergovernmental Panel on Climate Change; Cambridge University Press: Cambridge, UK, 2007.

2. World Economic Forum. Shaping the Future of Construction: A Breakthrough in Mindset and Technology. In Proceedings of the 2016 World Economic Forum, Geneva, Switzerland, 20-23 January 2016.

3. Van Bueren, E.; De Jong, J. Establishing sustainability: Policy successes and failures. Build. Res. Inf. 2007, 35, 543-556. [CrossRef]

4. Yudelson, J. Reinventing Green Building: Why Certification Systems Aren't Working and What We Can Do about It; New Society Publishers: Gabriola Island, BC, Canada, 2016.

5. Kibert, C. The next generation of sustainable construction. Build. Res. Inf. 2007, 35, 595-601. [CrossRef]

6. Wolstenholme, A.; Austin, S.; Bairstow, M.; Blumenthal, A.; Lorimer, J.; McGuckin, S. Never Waste a Good Crisis: A Review of Progress since Rethinking Construction and Thoughts for Our Future; Constructing Excellence: London, UK, 2009.

7. Lees, T.; Sexton, M. An evolutionary innovation perspective on the selection of low and zero-carbon technologies in new housing. Build. Res. Inf. 2013, 42, 276-287. [CrossRef]

8. Circo, C.J. Using mandates and incentives to promote sustainable construction and green building projects in the private sector: A call for more state land use policy initiatives. Penn State Law Rev. 2008, 112, 732-782. 
9. Hillary, R.; Thorsen, N. Regulatory and self-regulatory measures as routes to promote cleaner production. J. Clean. Prod. 1999, 7, 1-11. [CrossRef]

10. Lenox, M.J. The Role of Private Decentralized Institutions in Sustaining Industry Self-Regulation. Organ. Sci. 2006, 17, 677-690. [CrossRef]

11. Cole, R.J. Building Green: Moving beyond Regulations and Voluntary Initiatives; Policy Options: Montreal, QC, Canada, 2005; pp. 53-60.

12. Schweber, L. The Cultural Role of Science in Policy Implementation: Voluntary Self-Regulation in the UK Building Sector. In Fields of Knowledge: Science, Politics and Publics in the Neoliberal Age; Frickel, S., Hess, D.J., Eds.; Emerald Group Publishing: Bingley, UK, 2014; pp. 157-191.

13. Ding, G.K. Sustainable construction-The role of environmental assessment tools. J. Environ. Manag. 2008, 86, 451-464. [CrossRef]

14. Schweber, L. Jack-in-the-black-box: Using Foucault to explore the embeddedness and reach of building level assessment methods. Energy Res. Soc. Sci. 2017, 34, 294-304. [CrossRef]

15. Schweber, L. The effect of BREEAM on clients and construction professionals. Build. Res. Inf. 2013, 41, 129-145. [CrossRef]

16. Braulio-Gonzalo, M.; Bovea, M. Relationship between green public procurement criteria and sustainability assessment tools applied to office buildings. Environ. Impact Assess. Rev. 2020, 81, 106310. [CrossRef]

17. Haapio, A.; Viitaniemi, P. A critical review of building environmental assessment tools. Environ. Impact Assess. Rev. 2008, 28, 469-482. [CrossRef]

18. Alyami, S.H.; Rezgui, Y. Sustainable building assessment tool development approach. Sustain. Cities Soc. 2012, 5, 52-62. [CrossRef]

19. Doan, D.T.; Hoseini, A.G.; Naismith, N.; Zhang, T.; Tookey, J. A critical comparison of green building rating systems. Build. Environ. 2017, 123, 243-260. [CrossRef]

20. Ahmad, T.; Aibinu, A.A.; Stephan, A. Managing green building development-A review of current state of research and future directions. Build. Environ. 2019, 155, 83-104. [CrossRef]

21. Boxenbaum, E.; Georg, S.; De Linde, G.G.; Reijonen, S. How Standards Enable the Creation of Sustainable Construction as a New Category; Paper Presented at Rethinking Organizations Workshop: Grenoble, France, 2014.

22. York, J.G.; Vedula, S.; Lenox, M.J. It's Not Easy Building Green: The Impact of Public Policy, Private Actors, and Regional Logics on Voluntary Standards Adoption. Acad. Manag. J. 2018, 61, 1492-1523. [CrossRef]

23. Jones, J.; York, J.G.; Vedula, S.; Conger, M.; Lenox, M. The Collective Construction of Green Building: Industry Transition Toward Environmentally Beneficial Practices. Acad. Manag. Perspect. 2019, 33, 425-449. [CrossRef]

24. Boxenbaum, E.; Georg, S. The Role of Standards and Exemplars in Consolidating Labels for Sustainable Construction. In Labelling the Economy; Laurent, B., Mallard, A., Eds.; Palgrave Macmillan: Singapore, 2020; pp. 125-150.

25. Fligstein, N.; McAdam, D. A Theory of Fields; Oxford University Press: New York, NY, USA, 2012.

26. Fligstein, N.; McAdam, D. Toward a General Theory of Strategic Action Fields. Sociol. Theory 2011, $29,1-26$. [CrossRef]

27. Fligstein, N. Understanding stability and change in fields. Res. Organ. Behav. 2013, 33, 39-51. [CrossRef]

28. Barnett, M.L.; King, A.A. Good Fences Make Good Neighbors: A Longitudinal Analysis of an Industry Self-Regulatory Institution. Acad. Manag. J. 2008, 51, 1150-1170. [CrossRef]

29. King, A.A.; Lenox, M.J.; Terlaak, A. The Strategic Use of Decentralized Institutions: Exploring Certification with the ISO 14001 Management Standard. Acad. Manag. J. 2005, 48, 1091-1106. [CrossRef]

30. Aguayo, B.E.C.; Barriga, J. Behind certification and regulatory processes: Contributions to a political history of the Chilean salmon farming. Glob. Environ. Chang. 2016, 39, 81-90. [CrossRef]

31. Sarkar, A. Green Branding and Eco-innovations for Evolving a Sustainable Green Marketing Strategy. Asia-Pac. J. Manag. Res. Innov. 2012, 8, 39-58. [CrossRef]

32. Suchman, M.C. Managing legitimacy: Strategic and institutional approaches. Acad. Manag. Rev. 1995, 20, 571-610. [CrossRef]

33. Phillips, R. Stakeholder Legitimacy. Bus. Ethic Q. 2003, 13, 25-41. [CrossRef]

34. Dawson, N.L.; Segerson, K. Voluntary Agreements with Industries: Participation Incentives with Industry-Wide Targets. Land Econ. 2008, 84, 97-114. [CrossRef] 
35. Foster, A.D.; Gutierrez, E. The Informational Role of Voluntary Certification: Evidence from the Mexican Clean Industry Program. Am. Econ. Rev. 2013, 103, 303-308. [CrossRef]

36. Tröster, R.; Hiete, M. Success of voluntary sustainability certification schemes-A comprehensive review. J. Clean. Prod. 2018, 196, 1034-1043. [CrossRef]

37. Gruneberg, S.L. Construction Economics; Macmillian Press: London, UK, 1997.

38. Gruneberg, S.; Francis, N. The Economics of Construction. The Economics of Big Business; Agenda Publishing: Newcastle upon Tyne, UK, 2019.

39. Leiringer, R.; Green, S.D.; Raja, J.Z. Living up to the value agenda: The empirical realities of through-life value creation in construction. Constr. Manag. Econ. 2009, 27, 271-285. [CrossRef]

40. Winch, G.; Leiringer, R. Owner project capabilities for infrastructure development: A review and development of the "strong owner" concept. Int. J. Proj. Manag. 2016, 34, 271-281. [CrossRef]

41. Dainty, A.; Leiringer, R.; Fernie, S.; Harty, C. BIM and the small construction firm: A critical perspective. Build. Res. Inf. 2017, 45, 696-709. [CrossRef]

42. Bresnen, M.; Goussevskaia, A.; Swan, J. Embedding New Management Knowledge in Project-Based Organizations. Organ. Stud. 2004, 25, 1535-1555. [CrossRef]

43. Cole, R.J. The privatization of global environmental assessment methods. Build. Res. Inf. 1998, $26,3-16$. [CrossRef]

44. Rees, W.E. The ecological crisis and self-delusion: Implications for the building sector. Build. Res. Inf. 2009, 37, 300-311. [CrossRef]

45. Du Plessis, C.; Cole, R.J. Motivating change: Shifting the paradigm. Build. Res. Inf. 2011, 39, 436-449. [CrossRef]

46. Gabe, J.; Christensen, P.H. Information or Marketing? Lessons from the History of Private-Sector Green Building Labelling. In Sustainable Real Estate; Palgrave Macmillan: Cham, Switzerland, 2018; pp. 115-163.

47. Cole, R.J.; Valdebenito, M.J. The importation of building environmental certification systems: International usages of BREEAM and LEED. Build. Res. Inf. 2013, 41, 662-676. [CrossRef]

48. Cole, R.J. Building Environmental Assessment in a Global Market. Int. J. Sustain. Build. Technol. Urban Dev. 2010, 1, 11-14. [CrossRef]

49. Cole, R.J. Shared markets: Coexisting building environmental assessment methods. Build. Res. Inf. 2006, 34, 357-371. [CrossRef]

50. BCA. Singapore Leading the Way for Green Buildings in the Tropics; Building and Housing Authority: Singapore, 2013.

51. Chan, I.; Leung, M.Y. Sustainable Development Worldwide: Costs of Green Buildings; Hong Kong Institute of Surveyors: Hong Kong, China, 2017.

52. HKSAR. LCQ4: Policies and Measures to Promote Green Buildings; HKSAR: Hong Kong, China, 2015.

53. Inkoom, E.E.; Leiringer, R. Exploring the dynamic nature of the evolution of Building Environmental Assessment Methods (BEAMs): A call for a diachronic analysis of BEAMs. Eng. Proj. Organ. J. 2016, 6, 104-114. [CrossRef]

54. May, P.J.; Koski, C. State Environmental Policies: Analyzing Green Building Mandates. Rev. Policy Res. 2007, 24, 49-65. [CrossRef]

55. Todd, J.A.; Pyke, C.R.; Tufts, R. Implications of trends in LEED usage: Rating system design and market transformation. Build. Res. Inf. 2013, 41, 384-400. [CrossRef]

56. Pettinicchio, D. Strategic Action Fields and the Context of Political Entrepreneurship: How Disability Rights Became Part of the Policy Agenda. Intersect. Soc. Chang. 2013, 79-106. [CrossRef]

57. Furnari, S. Institutional fields as linked arenas: Inter-field resource dependence, institutional work and institutional change. Hum. Relat. 2016, 69, 551-580. [CrossRef]

58. Taylor, B.J. Strategic Action Fields in US Higher Education: The 1939 Mercer University Heresy Trial. J. Hist. Sociol. 2014, 29, 359-384. [CrossRef]

59. Moulton, S.; Sandfort, J.R. The Strategic Action Field Framework for Policy Implementation Research. Policy Stud. J. 2016, 45, 144-169. [CrossRef]

60. Bourdieu, P.; Wacquant, L.J. An Invitation to Reflexive Sociology; The University of Chicago Press: Chicago, IL, USA, 1992.

61. Dyer, W.B.; Wilkins, A.L. Better Stories, Not Better Constructs, to Generate Better Theory: A Rejoinder to Eisenhardt. Acad. Manag. Rev. 1991, 16, 613-619. [CrossRef] 
62. Ade, R.; Rehm, M. The unwritten history of green building rating tools: A personal view from some of the 'founding fathers'. Build. Res. Inf. 2019, 48, 1-17. [CrossRef]

63. HKGBC. BEAM Plus Project Directory \& Statistics. 2020. Available online: https://www.hkgbc.org.hk/eng/ beam-plus/beam-plus-dir-stat/BEAMPlusDirectory.jsp (accessed on 20 August 2020).

64. BEAM Society. BEAM Plus for New Buildings Version 1.2; BEAM Society: Hong Kong, China, 2012.

65. BEAM Society. The Fundamentals and Principles of HK-BEAM; BEAM Society: Hong Kong, China, 2012.

66. Qian, Q.K.; Fan, K.; Chan, E.H.W. Regulatory incentives for green buildings: Gross floor area concessions. Build. Res. Inf. 2016, 44, 675-693. [CrossRef]

67. CIC. Cost-Benefit-Analysis for Implementing Green Buildings Promotion Incentives with Transaction Costs Considerations; Construction Industry Council: Hong Kong, China, 2018.

68. Ade, R.; Rehm, M. Reaching for the stars: Green construction cost premiums for Homestar certification. Constr. Manag. Econ. 2019, 38, 570-580. [CrossRef]

69. Hwang, B.-G.; Shan, M.; Lye, J.-M. Adoption of sustainable construction for small contractors: Major barriers and best solutions. Clean Technol. Environ. Policy 2018, 20, 2223-2237. [CrossRef]

70. Hwang, B.-G.; Zhu, L.; Wang, Y.; Cheong, X. Green Building Construction Projects in Singapore: Cost Premiums and Cost Performance. Proj. Manag. J. 2017, 48, 67-79. [CrossRef]

71. Schweber, L.; Haroglu, H. Comparing the fit between BREEAM assessment and design processes. Build. Res. Inf. 2014, 42, 300-317. [CrossRef]

72. Wassermann, S.; Reeg, M.; Nienhaus, K. Current challenges of Germany's energy transition project and competing strategies of challengers and incumbents: The case of direct marketing of electricity from renewable energy sources. Energy Policy 2015, 76, 66-75. [CrossRef]

73. HKSAR. Ordinance \& Regulations. In Waste Disposal Ordinance (Cap. 354); HKSAR: Hong Kong, China, 2005.

74. Gou, Z.; Xie, X. Evolving green building: Triple bottom line or regenerative design? J. Clean. Prod. 2017, 153, 600-607. [CrossRef]

Publisher's Note: MDPI stays neutral with regard to jurisdictional claims in published maps and institutional affiliations.

(C) 2020 by the author. Licensee MDPI, Basel, Switzerland. This article is an open access article distributed under the terms and conditions of the Creative Commons Attribution (CC BY) license (http://creativecommons.org/licenses/by/4.0/). 